\title{
Nanotechnology in Cancer Diagnosis and Treatment
}

\author{
Somaia Said Abd El-Karim, Magdy Ibrahim El-Zahar and Manal Mohamed Anwar \\ Therapeutical Chemistry Department, National Research Centre, Dokki, Cairo 12622, Egypt
}

\begin{abstract}
Nanotechnology refers to research and technology development at the atomic, molecular, and macromolecular scale, leading to the controlled manipulation and study of structures and devices with length scales in the 1-100 nanometers range. Objects at this scale, such as "nanoparticles," take on novel properties and functions that differ markedly from those seen in the bulk scale. The small size, surface tailor ability, improved solubility, and multifunctional of nanoparticles open many new research avenues for biologists. Nanoparticles are classified into inorganic nanoparticles such as gold nanoparticles and organic nanoparticles such as carbon nanotubes and dendrimers. Different types of nanoparticals such as nanocrystals, liposomes, polymeric nanoparticles, dendrimers, quantum dots and superparamagnetic nanoparticles illustrated different examples of promising nanoparticles for cancer treatment and imaging.
\end{abstract}

Key words: Nanotechnology, cancer, nanoparticles, toxicity.

\section{Introduction}

Nanotechnology literally means any technology on a nanoscale that has applications in the real world. Nanotechnology deals with the physical, chemical, and biological systems at dimensions ranging from single atoms or molecules to submicron and the integration of the nanoparticles into larger systems. Nanotechnology constitutes one of the most important factors that affect our social economy in the last century, comparable to that of semiconductor technology, information technology, or cellular and molecular biology. Science and technology research in nanotechnology promises breakthroughs in areas such as materials and manufacturing, nanoelectronics, medicine and healthcare, energy, biotechnology, information technology, and national security. It is widely felt that nanotechnology will be the next Industrial Revolution [1].

The discovery of novel materials, processes, and phenomena at the nanoscale and the development of new experimental and theoretical techniques for research provide fresh opportunities for the

Corresponding author: Somaia Said Abd El-Karim, associate professor, research field: medicinal chemistry. E-mail address: somaia_elkarim@hotmail.com. development of innovative nanosystems and nanostructured materials. The properties of materials at the nanoscale can be very different from those at a larger scale. When the dimension of a material is reduced from a large size, the properties remain the same at first, and then small changes occur, until finally when the size drops below $100 \mathrm{~nm}$, dramatic changes in properties can occur. If only one length of a three-dimensional nanostructure is of nanodimension, the structure is referred to as a quantum well; if two sides are of nanometer length, the structure is referred to as a quantum wire. A quantum dot has all three dimensions in the nano range. The term quantum is associated with these three types of nanostructures because the changes in properties arise from the quantum-mechanical nature of physics in the domain of the ultrasmall. Materials can be nanostructured for new properties and novel performance. This field is opening new avenues in science and technology [1].

\section{Nanotechnology in Cancer Treatment}

\subsection{Cancer}

Cancer is one of the major causes of mortality in the United States, and the worldwide incidence of cancer 
continues to increase. The common strategy of cancer treatments is restricted to surgical resection of the tumor followed by either chemotherapy or radiation or combination of both of them. Frequent challenges encountered by current cancer therapies include nonspecific systemic distribution of antitumor agents, inadequate drug concentrations reaching the tumor, and the limited ability to monitor therapeutic responses. Poor drug delivery to the target site leads to various and significant complications, such as multidrug resistance [2].

Greater targeting selectivity and better delivery efficiency are the two major goals in the development of therapeutic agents or imaging contrast formulations. Ideally, a therapeutic drug would be selectively enriched in the tumor lesions with minimal damage to normal tissues. A rational approach to achieve these goals is to conjugate therapeutic drugs with mAbs (monoclonal antibodies) or other ligands that selectively bind to antigens or receptors that are usually abundantly or uniquely expressed on the tumor cell surface.

Recent developments in nanotechnology have provided researchers with new tools for cancer imaging and treatment. This technology has enabled the development of nanoscale devices that can be conjugated with several functional molecules simultaneously, including tumor-specific ligands, antibodies, anticancer drugs, and imaging probes. Since these nanodevices are 100 to 1,000-fold smaller than cancer cells, they can be easily transferred through leaky blood vessels and interact with targeted tumor-specific proteins both on the surface of and inside cancer cells. Therefore, their applications as cancer cell-specific delivery vehicles will be a significant addition to the currently available armory for cancer therapeutics and imaging [3-5].

By applying a vast and diverse array of nanoparticles, whose design derives from the engineering, chemistry, and medicine fields, to molecular imaging and targeted therapy, cancer nanotechnology promises solutions to several of the current obstacles facing cancer therapies [6-13].

\subsection{Drug Delivery with Nanoparticles}

Various drug delivery and drug targeting systems are currently applied or under development. Drug carriers include synthetic polymers, microcapsules, liposomes, dendrimers and many others and have one thing in common, namely the increased drug bio-availability and increased accumulation at the pathological site. This is especially important for the anticancer drugs, which should preferably be delivered locally with minimal or no effect onto the normal tissue. Drug containing nanoparticles can be made slowly biodegradable, thus delivering their pay-load at a controlled rate. Furthermore, nano-carriers are ideal entities to deliver poorly water-soluble agents at the desired site [14]. These factors may contribute considerably to the drug performance and clinical acceptance.

\subsubsection{Passive Targeting by Nanoparticles}

In order to acquire an efficacious therapeutic level of pharmaceuticals at a pathological site, nanoparticles should move from the circulation to the lesion. A prerequisite for this process is that the blood carrier stays in the blood long enough to slowly accumulate in the tissue of interest with affected and leaky vasculature. In cancer, this process of passive targeting takes place in a non-specific way through gaps into the tumor interstitial space. These gaps between the adjacent endothelial cells with a diameter up till $800 \mathrm{~nm}$ exist in neoangiogenic blood vessels which serve to supply the tumor with nutrients. Nanoparticles, carrying encapsulated drugs, extravasate into the tumor interstitial space and passively target the tumor tissue. Once the drug is locally released the local concentration becomes many times larger than after conventional systemic intravenous administration. The altered lymphatic drainage of the tumor contributes to this effect [15]. This type of passive targeting is known as "EPR" 
(enhanced permeation and retention) [16, 17] (Fig. 1).

This type of passive targeting has been used in the radiotherapeutic treatment of liver cancer. O’Neal et al. reported that nanoshells with diameters of $130 \mathrm{~nm}$ passed preferentially through the walls of vessels and were deposited in the surrounding tumorous tissue, where they are concentrated [18]. This phenomenon, termed extravasation, provides another passive method to concentrate the particles of up to $300 \mathrm{~nm}$ diameters in some tumors or inflamed tissues [19].

\subsubsection{Active Targeting of Nanoparticles}

Larger tumors show poor vascularization, especially inside the necrotic areas, which prevents the localization of the nanoparticles and makes local drug deposition impossible. Because of these limitations the next generation of nanoparticle delivery systems, smart nanocarriers, is being developed.

Active targeting employs specific modification of drug/drug carrier nanosystems with active agents having selective affinity for recognizing and interacting with a specific cell, tissue or organ in the body. Coupling of drug carrier nanosystems to ligands allows import of thousands of drug molecules by means of receptor targeted ligands. A more sophisticated approach is to modify the surface of the nanoparticle by the addition of an antibody or ligand with affinity for the desired target. The probability of an interaction between nanoparticles and the immune system can be substantially reduced by using so-called stealth technologies. These involve coating the nanoparticle with a self-assembled layer of a thiolated PEG (poly-ethyleneglycol) [20, 21] or liposome, rendering the surfaces of these particles inert with respect to protein absorption. Paradoxically, if a particle is so well coated that it becomes invisible to the immune system, it will also probably lose its ability to bind to specific receptors.

An example is the nanoparticle that targets the folic

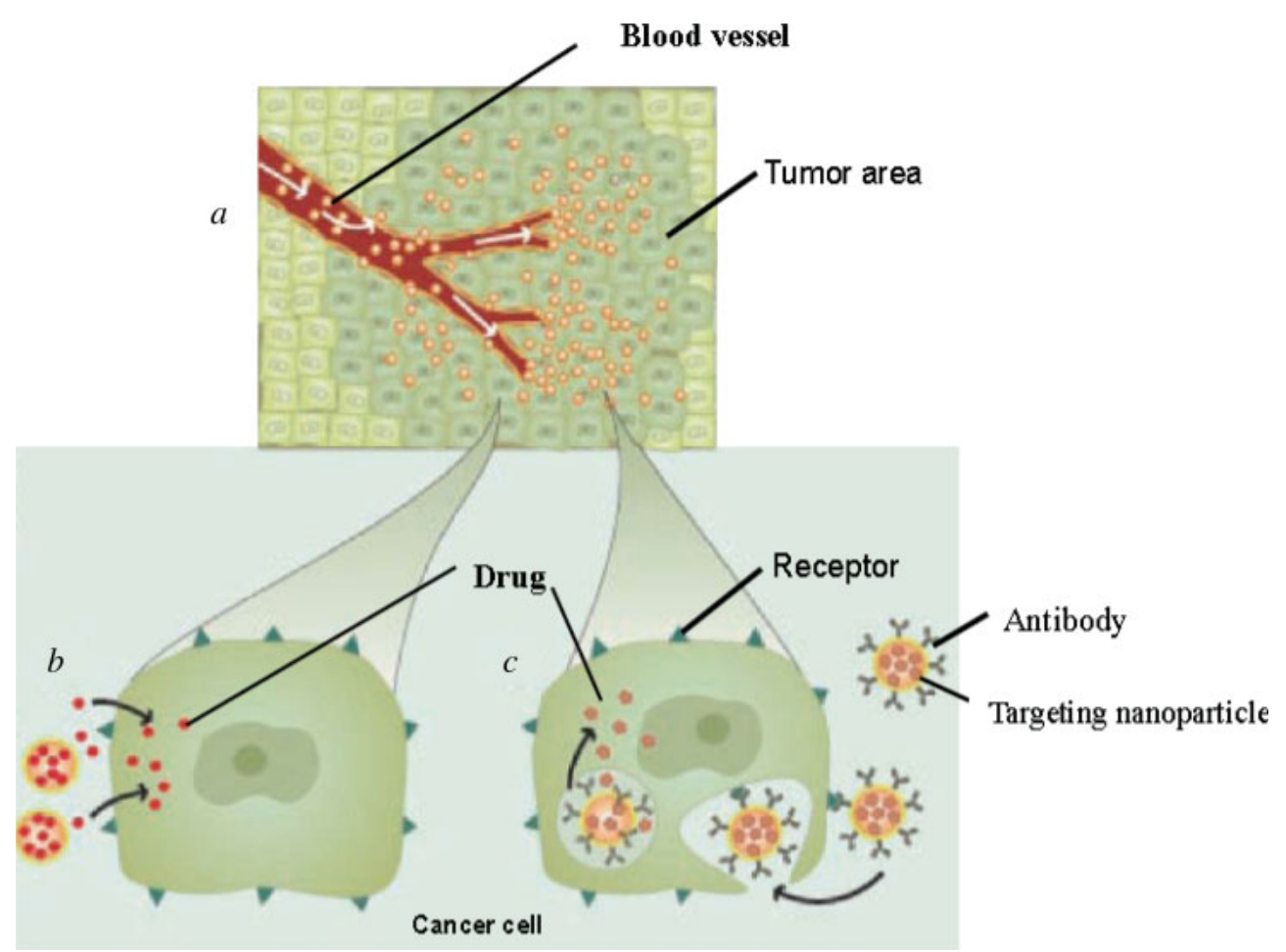

Fig. 1 Schematic diagram showing the passive or ligand-targeted accumulation of drug delivery system in tumor therapy through the enhanced permeability and retention effect.

(a) Nanoparticles containing an anticancer drug extravasate from the blood through gaps in vascular endothelial cells and accumulate in tumor tissue, but not in normal tissue. (b) Drug is released from the nanoparticles in the vicinity of tumor cells and taken up into the cells. (c) Ligand-targeted nanoparticles containing anticancer drugs bind to cell surface receptors, which trigger internalization of the nanoparticles into endosomes. A proportion of encapsulated materials escapes the endosomes and is trafficked to the intracellular site of action [25]. 
acid receptor which is over-expressed in various human carcinomas [22]. The nanoparticle conjugated with folic acid as a receptor seeker and containing methotrexate as a chemotherapeutic agent has been demonstrated to enter the cancer cell and inhibit its growth [23]. A widely investigated modality for the recognition of cancer cells is the use of monoclonal antibodies. The recognition of cell surface antigens has been successful in various instances, especially in non-solid tumors [24].

\subsection{Nanoparticles Architecture}

\subsubsection{Nanocrystals}

Nanocrystals consist of aggregates of around hundreds of drug molecules combined in a single crystal with a thin coating as a surfactant [26, 27]. Nanocrystals are advantageous as an oral delivery system for various drugs as problems as poorly drug solubility are solved in this way with no potential toxicity.

\subsubsection{Quantum Dots}

Semiconductor QDs (quantum dots) are rapidly emerging as popular luminescence probes for many biological and biomedical applications owing to their extremely small sizes (approximately $10 \mathrm{~nm}$ in diameter), high photostability, tunable optical properties, and multimodality [28-30]. Such inorganic-organic composite nanomaterials have shown extreme efficiency in cancer diagnosis in vivo, with their small sizes which facilitate unimpeded systemic circulation and attached targeting molecules, allowing for specific "honing in" at neoplastic sites [31, 32]. Similar to other nanoparticles, QDs can be modified via conjugation of various surface molecules for targeted delivery [33, 34]. QDs also provide sufficient surface area to attach therapeutic agents for simultaneous drug delivery and in vivo imaging [35] as well as for tissue engineering [36]. In vivo cancer targeting and imaging in living animals by QDs was first demonstrated by Gao and colleagues [37], where both subcutaneous injection of QD-tagged prostate cancer cells and systemic injection of multifunctional QD probes were used to achieve sensitive and multicolor fluorescence imaging of cancer cells. In a recent a study, Bagalkot and colleagues [38] used QD-Apt (aptamer)-Dox (doxorubicin) multifunctional conjugate to carry doxorubicin to the targeted prostate cancer cells. Sensing of doxorubicin by activating the fluorescence of QD enables the nanoconjugate to imagine the cancer cells.

Nevertheless, the applications of QDs are also found in the NIR (near infrared) imaging (700-1000 nm) [39]. The use of NIR-QDs can maximize the depth of tissue penetration, allowing for more accurate and sensitive detection of photons in vivo, which is limited by absorption and light scattering in conventional imaging.

\subsubsection{Carbon Nanotubes}

Carbon nanotubes are sheets of atoms in the form of tubes of which the size mimics the physical dimensions of nucleic acids. They are considered optimal vehicles for the delivery of genes, peptides and proteins [40] (Fig. 2).

\subsubsection{Liposomes}

Liposomes are self-assembling, spherical, closed colloidal structures which drug molecules are entrapped in a central aqueous space surrounded by a membranous lipid bilayer of phospholipids (Fig. 3). Liposomes are the most studied formulation of nanoparticle for drug delivery. Liposomal formulations

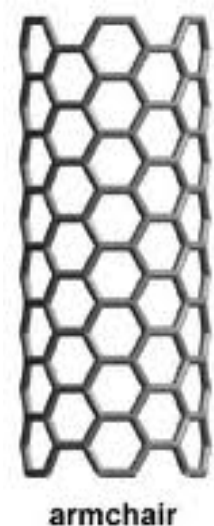

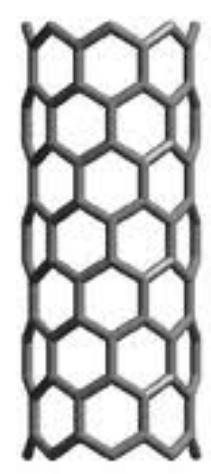

zigzag

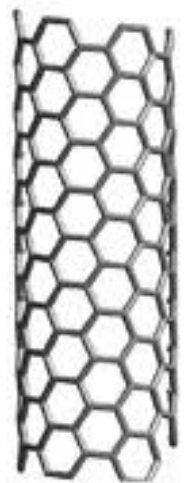

chiral
Fig. 2 Molecular diagram of different carbon nanotube structures (from coecs.ou.edu). 


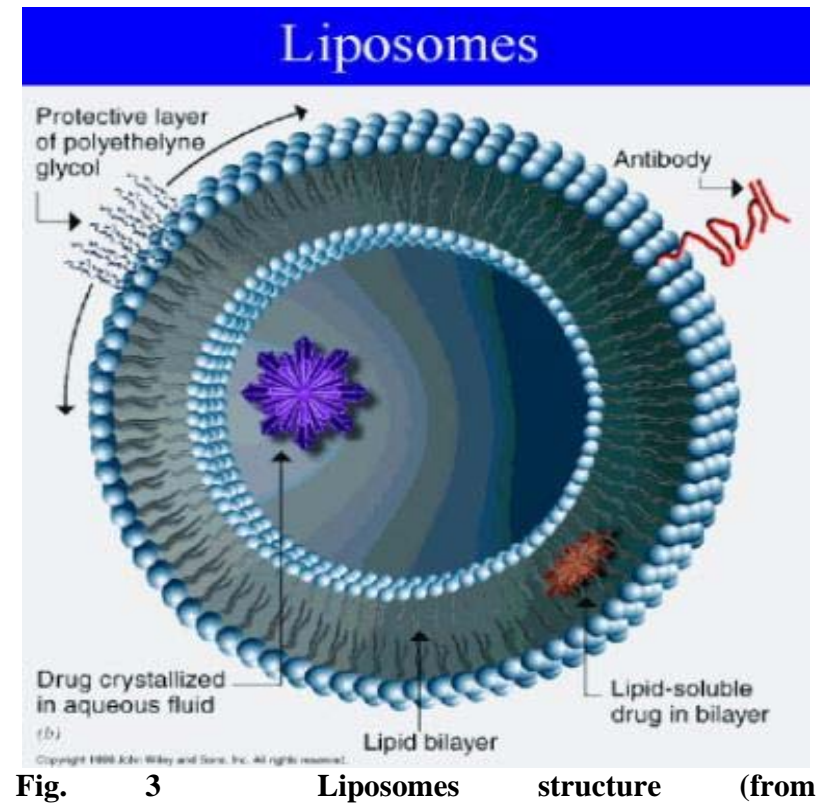

www.nanopharmaceuticals.org).

have shown an ability to improve the pharmacokinetics and pharmacodynamics of associated drugs [41]. To date, liposome-based formulations of several anticancer agents (Stealth liposomal doxorubicin [Doxil $]^{\circledR}$, liposomal doxorubicin [Myocet] ${ }^{\circledR}$, and liposomal daunorubicin [DaunoXome] ${ }^{\circledR}$ have been approved for the treatment of metastatic breast cancer [42-46].

\subsubsection{Solid Lipid Nanoparticles}

Solid lipid nanoparticles are colloidal carriers consisting of a monolayer of phospholipid coating around a solid hydrophobic core containing the drug in a high melting fat matrix. The drug, being in a solid state, is released slowly from the particle and this delivery system may offer advantageous in terms of biodegradation and tolerance [47].

\subsubsection{Polymeric Nanoparticles}

Polymeric nanoparticles typically consist of polylactic acid, polyglycolic acid or acrylates. These colloidal carriers, prepared as nanospheres or nanocapsules, contain the drug in an entrapped or encapsulated form. Their design allows for the highly concentrated drug delivery at a desired location, but the main obstacle for human use is their cytotoxicity for macrophages [48-51].

\subsubsection{Dendrimers}

Dendrimers are highly branched macromolecules with a controlled three-dimensional architecture [52-54]. The branches are structured around a designed central core and, like a tree, expand outward via polymerization reactions, which allow for exact shaping of the nanoparticle. Dendrimers synthesized from three-dimensional PAMAM (polyamindoamine) contain tertiary amines and amide linkages. The branched structure makes it possible to attach other molecules like drugs and contrast agents to the surface. Toxicity is minimized by "hiding" the drug molecules in the interior of the dendrimer. Dendrimers have three components: an initiator core, branches, and terminal functional groups. The initiator core is in the heart of the molecule, and the branches extend outward from it. The G0 (monomers attached to the core), are called G1 (first generation monomers) and G2 (two second generation monomers) are attached to the each first generation monomers. Furthermore, terminal groups can be modified to obtain both a charged, and hydrophilic or lipophilic function for the desired biological and drug delivery application [55] (Fig. 4).

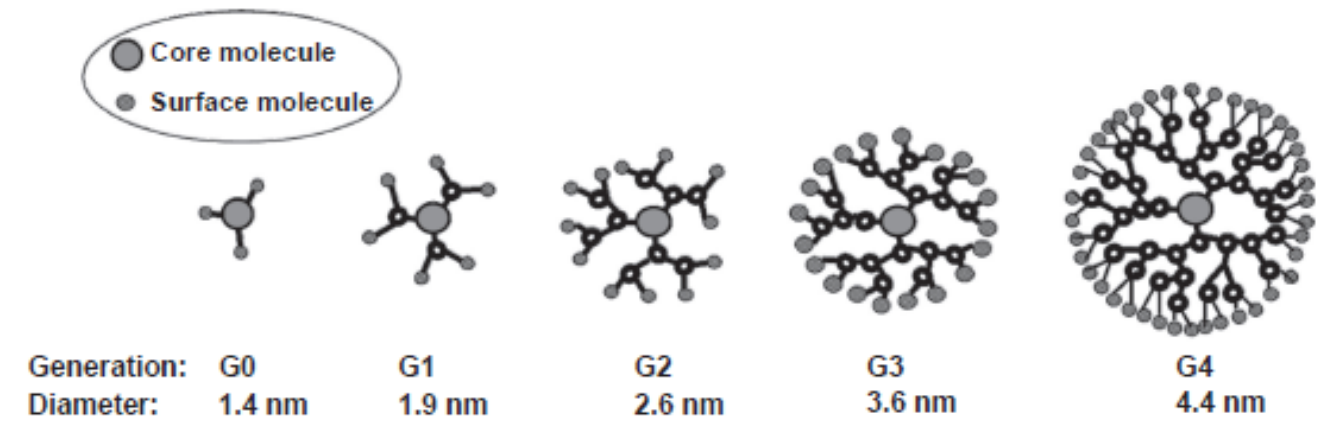

Fig. 4 Graphical representation of dendrimers from core to generation $G=4$, showing the linear increase in diameter [56]. 


\subsubsection{Viruses}

Viruses have the capacity to target cancer cells and deliver drugs in both the cytosol and the cell nucleus. The functionality of several nanocarriers can, at least theoretically, be improved by constructing hybrid virus nanoparticles which could use the targeting virus characteristics to selectively invade the cancer cells, using a similar mechanism as proposed for gene therapy [57].

\subsection{Cancer Imaging with Nanoparticles}

\subsubsection{Optical Imaging with Quantum Dots}

Nanocrystals possess unique properties which make them suitable for optical imaging. Optical fluorescent imaging is achieved using these nanocrystals made of cadmium selenide, cadmium sulfide or cadmium telluride, surrounded by an inert polymer coating. These Qdots (quantum dots) are used as fluorescent labels of live cells [27].

Qdots absorb white light and re-emit the light a few nanoseconds later. The particle can be functionalized "active targeting" by way of molecular recognition systems like monoclonal antibodies attached to the outer coating against a specific target or via receptor interactions with specialized ligands [58].

\subsubsection{MRI (Magnetic Resonance Imaging)}

MRI offers a wealth of information on local biology and pathology based on nuclear magnetic resonance signals, received from hydrogen nuclei present in the organism under different (patho) physiological conditions. MRI lends itself exquisitely to creating three dimensional images of the body and can be used to characterize many types of tissues. Tumors can be highlighted with contrast agents (e.g. gadolinium chelates) which help to enhance the image contrast for diagnosis and the assessment of treatment response [59].

For MRI much attention has been devoted to the development of superparamagnetic nanoparticles for contrast enhancement. These particles consist of an inorganic core of iron oxide $\left(\mathrm{Fe}^{2+}\right.$ or $\mathrm{Fe}^{3+}$ salts), often coated with polyethylene glycol or dextran. These nanoparticles possess large magnetic moments and disturb a homogeneous magnetic field and they are categorized in two groups:

SPIOs (superparamagnetic iron oxides) with an average size greater than $50 \mathrm{~nm}$.

USPIOs (ultra small paramagnetic iron oxides) with an average size lower than $50 \mathrm{~nm}$ allowing longer circulation and final removal by the lymphatic system.

Commercially available SPIOs as MRI contrast enhancers include Lumirem ${ }^{\circledR}$ and Endorem ${ }^{\circledR}$, respectively in clinical use for imaging of the gastro intestinal tract and for liver and spleen tissue [60]. A commercially available USPIO is Sinerem ${ }^{\circledR}$ which can be used for blood pool visualization with MRI [61].

For active targeting a second generation of superparamagnetic nanoparticles (also known as CLIOs (cross-linked iron oxides)) have been generated. They can be conjugated to monoclonal antibodies or receptor-seeking agents. This principle of active targeting is well known in diagnostic and therapeutic nuclear medicine [62].

2.4.3 Nuclear Medicine Imaging and Therapy

In the field of therapeutic nuclear medicine an interesting development comes from the synthesis of lanthanide nanoparticles in the form of clusters of ${ }^{153} \mathrm{Sm}$-atoms, meant for peptide mediated tumor treatment [63]. Liposomes can be used to carry radioactive compounds as radiotracers can be linked to multiple locations in liposomes. Delivery of agents to the RES (reticuloendothelial system) is easily achieved, since most conventional liposomes are trapped by the RES. For the purpose of delivery of agents to target organs other than RES, long-circulating liposomes have been developed by modifying the liposomal surface [64]. In a recent study ${ }^{64} \mathrm{Cu}$-radiolabeled folate-conjugated SCKs (shell cross-linked nanoparticles) were evaluated as candidate agents to shuttle radionuclides and drugs into tumors [65]. 


\subsubsection{Ultrasonography}

The growth of nanotechnology has opened the way to improve the quality of ultrasound methods for medical diagnosis. Microbubble contrast agents are miniature gas bubbles, which can remain suspended in the circulation for an extended period. During scanning the energy produced by the ultrasound beam causes rapid contraction and expansion of the bubble leading to contrast enhancement [66].

\section{Promising Nanoparticles for Cancer Treatment}

\subsection{Gold Nanoparticles}

Nanoparticles of gold, which are in the size range 10-100 nm, undergo a plasmon resonance with light. This is a process whereby the electrons of the gold resonate in response to incoming radiation causing them to both absorb and scatter light. This effect can be harnessed to either destroy tissue by local heating or release payload molecules of therapeutic importance. Gold nanoparticles can also be conjugated to biologically active moieties, providing possibilities for targeting to particular tissues [67-69].

Many biodiagnostic applications of gold nanoparticles, or electrodes, have been developed since the 1970s [70-72]; however, the rational application of gold nanoparticles in therapeutic situations is a largely undeveloped field. The properties of gold nanoparticles that make them particularly suitable for therapeutic applications: resistance to oxidation, antibodies and other biological molecules can be readily attached to the surface of gold nanoparticles, and the plasmon resonances of gold nanoparticles of certain shapes cause them to have photon capture cross-sections that are four to five orders of magnitude greater than those of photothermal dyes [73]. These attributes are exploited to obtain the localized heating, or drug release, underlying the therapeutic applications.

El-Sayed et al. [74] reported that colloidal gold nanoparticles are found in dispersed and aggregated forms within the cell cytoplasm and provide anatomic labeling information, but their uptake is nonspecific for malignant cells. The anti-EGFR (anti-epidermal growth factor receptor) antibody conjugated nanoparticles specifically and homogeneously binds to the surface of the cancer type cells with $600 \%$ greater affinity than to the noncancerous cells. This specific and homogeneous binding is found to give a relatively sharper SPR absorption band with a red shifted maximum compared to that observed when added to the noncancerous cells. These results suggest that the SPR (surface plasmon resonance) scattering imaging or SPR absorption spectroscopy generated from the antibody conjugated gold nanoparticles can be useful in molecular biosensor techniques for the diagnosis and investigation of oral epithelial living cancer cells in vivo and in vitro.

The light scattering pattern of gold nanoparticles is significantly different when anti-EGFR antibodies were conjugated to gold nanoparticles before incubation with the cells. The HaCaT noncancerous cells are poorly labeled by the nanoparticles and the cells could not be identified individually. When the conjugates are incubated with HOC and HSC cancerous cells for the same amount of time (Fig. 5), the nanoparticles were found on the surface of the cells, especially on the cytoplasm membranes for HSC cancer cells. This contrast difference is due to the specific binding of over-expressed EGFR on the cancer cells with the anti-EGFR antibodies on the gold surface. The nanoparticles are also found on the HaCaT noncancerous cells due to part of the specific binding, but mostly due to the nonspecific interactions between the antibodies and the proteins on the cell surface, and thus the nanoparticles are randomly distributed on the whole cells. The nonspecific interaction between the anti-EGFR antibodies and the collagen matrix also exists, which is shown as the reddish scattering light of the gold nanoparticles on the collagen background.

From therapeutic properties of gold, the plasmon 

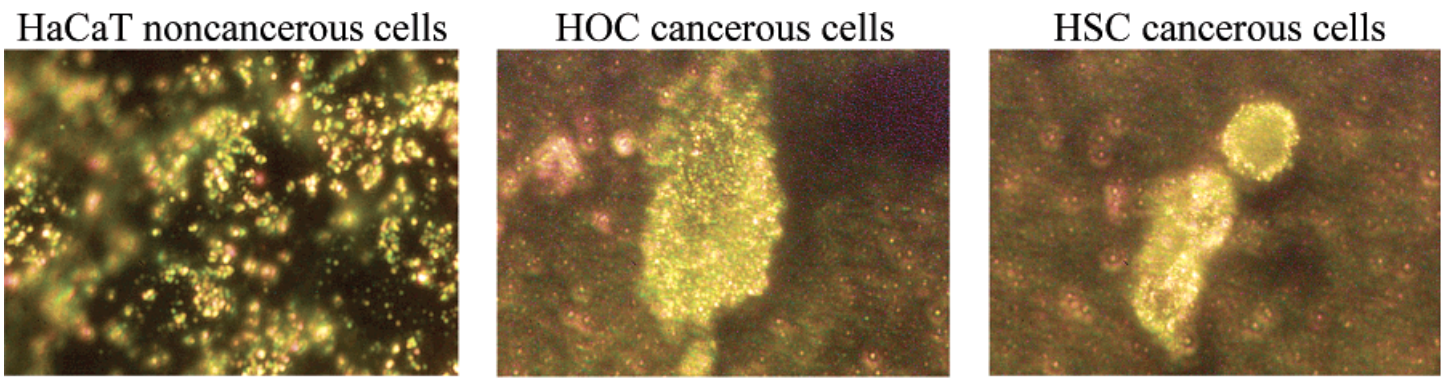

Fig. 5 Light scattering images and microabsorption spectra of HaCaT noncancerous cells (left column), HOC cancerous cells (middle column), and HSC cancerous cells (right column) after incubation with anti-EGFR antibody conjugated gold nanoparticles [75].

resonance for ordinary gold nanospheres is at about $520 \mathrm{~nm}$ (corresponding to green light), in the middle of the visible spectrum, but this can be red-shifted into the NIR (near infrared), with excitation wavelengths of 800-1200 nm required for more complex shapes, such as nanorods. This is useful because body tissue is moderately transparent to NIR light $[73,76]$ thereby providing an opportunity for therapeutic effects in deep tissues.

Hyperthermal therapy local application of heat is a well-known concept in therapeutic medicine that has been explored extensively for the treatment of cancer and other conditions. Energizing sources, such as infrared lamps, ultrasound or lasers, can be used in the process, but there is always the problem of limiting the heat generated to the region of the target tissue [77]. As mentioned earlier, the problem can be solved, in part, by using gold nanoparticles designed to absorb in the NIR spectrum such that the resulting localized heating causes irreversible thermal cellular destruction [78, 79].

Furthermore gold-on-silica nanoshells were used to target breast carcinoma cells, actively, using the HER2 (Human epidermal growth factor receptor 2) antibody [73]. This initial report was soon complemented by an account where the extravasation phenomenon was exploited to concentrate PEG-sheathed gold-on-silica nanoshells by passive targeting in an in vivo murine model [18]. In the Halas study, NIR irradiation led to a rise in the temperature of the target regions of between 40 to $50^{\circ} \mathrm{C}$, which selectively destroyed the carcinomas. The survival rate of mice treated in this manner was excellent compared with the controls.

Drug delivery includes encapsulating the payload inside a gold core-shell particle, impregnating a larger drug-containing nano- or microparticle with suitably designed gold particles or binding the payload to the outer surface of a gold nanoparticle. In all these cases, once the particle is at the target tissue, plasmonic heating leads to the release of the payload. In order to reach to the required accuracy for cancer cells targeting, and to obtain the correct excitation wavelength, laser should be the source of the used light (Fig. 6). Gold nanoparticles are sufficiently small that, in principle, they might be capable of delivering a payload of therapeutic agent, or heat, directly into the cytoplasm or the nucleus of the target cell [19, 80]. In both cases, the work exploited a polymer-gel impregnated with gold nanoshells to give gold-on-gold-sulphide coreshell particles.

It is apparent that gold nanoparticles have unique chemical and physical properties that facilitate and commend their use in these applications. In particular, their optical properties and flexible surface chemistry permit their use in photo-thermal therapeutic treatments. The efficiency of the process can be enhanced considerably by exploiting various passive targeting strategies to concentrate the nanoparticles in the tissue to be treated. In principle, active targeting of the nanoparticle is also possible, although further work on methods to evade the immune system en route 


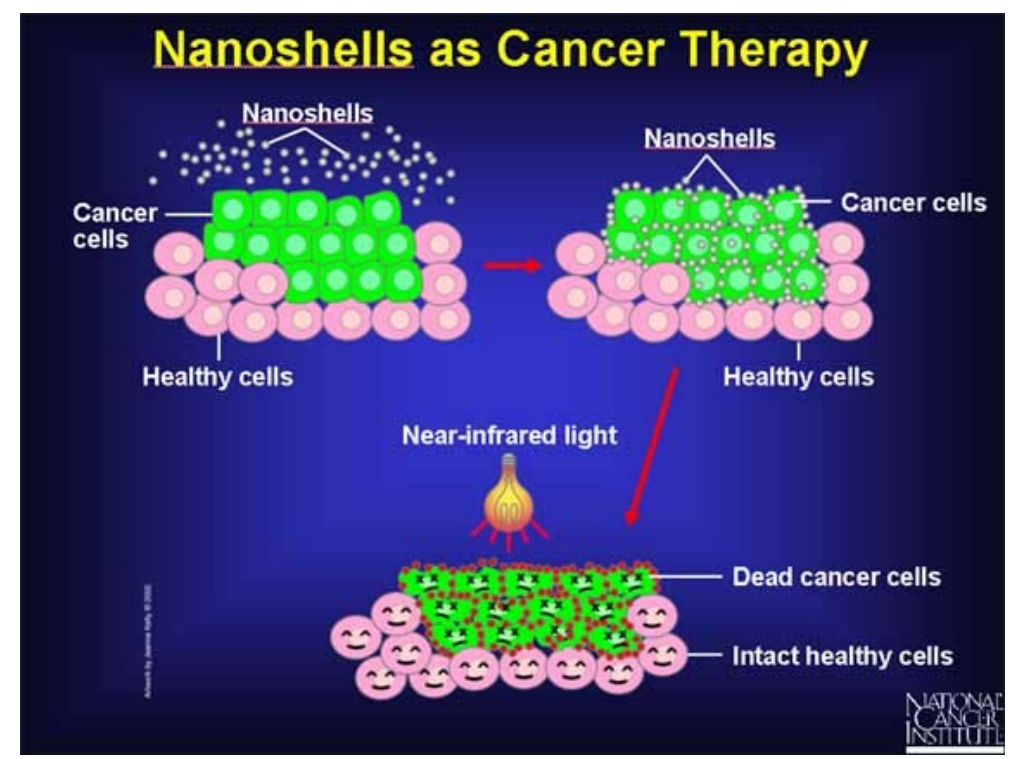

Fig. 6 Cancer treatment with gold nanoshell (from www.cancer.gov).

to the target also need to be considered.

\subsection{Methotrexate Nanoparticles}

A magnetic nanoparticle conjugate was developed that can potentially serve both as a contrast enhancement agent in magnetic resonance imaging and as a drug carrier in controlled drug delivery, targeted at cancer diagnostics and therapeutics. The conjugate is made of iron oxide nanoparticles covalently bound with MTX (methotrexate), a chemotherapeutic drug that can target many cancer cells whose surfaces are over-expressed by folate receptors. To conjugate the nanoparticles with methotrexate, they were first surface-modified with (3-aminopropyl) trimethoxysilane to form a self-assembled monolayer. Then amidation was carried out via covalent binding of the carboxylic acid moieties on MTX with the amine groups on the particle surface. Drug release experiments demonstrated that MTX was cleaved from the nanoparticles under low $\mathrm{pH}$ conditions mimicking the intracellular conditions in the lysosome. Cellular viability studies in human breast cancer cells (MCF-7) and human cervical cancer cells (HeLa) further demonstrated the effectiveness of such chemical cleavage of MTX inside the target cells through the action of intracellular enzymes. The intracellular trafficking model was supported through nanoparticle uptake studies which demonstrated that the cells expressing the human folate receptors internalized a higher level of nanoparticles than the negative control cells [81].

\subsection{Doxorubicin}

One of the most potent and widely used anticancer drugs is doxorubicin which works by inhibiting the synthesis of nucleic acids within the cancer cells [82]. Doxorubicin has a number of undesirable side effects such as cardiotoxicity and myelosuppression which lead to a very narrow therapeutic index. Various researchers have studied ways to target doxorubicin delivery to cancer tissues or at least to diminish its side effects. Conjugates of dextran and doxorubicin have been encapsulated in chitosan nanoparticles of approximately $100 \mathrm{~nm}$ diameter.

Nanoparticles were prepared of 200-250 nm diameters with in vitro release up to 1 month. Analysis in vivo of injected nanoparticles as compared with daily doxorubicin injections showed that a single injection of doxorubicin-PLGA conjugate nanoparticles could suppress tumor growth for up to 12 days, although not quite as well as daily 
doxorubicin injections at the levels tested [83].

\subsection{5-Fluorouracil}

Incorporation of 5-Fluorouracil has also been achieved using dendrimers of poly (amidoamine) modified with mPEG-500. The hydrophilicity of 5-Fluorouracil allowed it to complex with the dendrimers after simply incubating the polymer with the drug. For in vitro studies, PEGylated formulations showed release over $144 \mathrm{~h}$ (6 days) while non-PEGylated formulations had completed their release within 1 day. This confirms the formulations ability to control the 5-Fluorouracil release in vivo and the extension of that release by PEGylation of the polymers in the formulation [84].

\subsection{Poly[Lactic-Co-(Glycolic Acid)]-Grafted}

Hyaluronic Acid Copolymer Nanoparticles

PLGA-grafted HA copolymers were synthesized and utilized as target specific micelle carriers for DOX. Firstly, HA was dissolved in an anhydrous DMSO by nano-complexing with dimethoxy-PEG. Then the carboxylic groups of HA were chemically grafted with PLGA to get HA-g-PLGA copolymers. This process was used to graft the hydrophobic PLGA chains onto the hydrophilic HA chain. The resultant HA-g-PLGA self-assembled in aqueous solution to form multi-cored micellar aggregates and DOX was encapsulated during the self-assembly (Fig. 7). The advantages of DOX-loaded HA-g-PLGA micelle nanoparticles that they exhibited higher cellular absorption and more potent cytotoxicity than the free DOX against HCT-116 cells that over-expressed HA receptor. This indicates that they were absorbed by the cells via HA receptor-mediated endocytosis [85].

\subsection{Curcumin Nanoparticles}

Curcumin is a natural polyphenolic compound. It has shown promising chemopreventive and chemotherapeutic activities in cancer therapy. Although curcumin appeared to be a safe drug at small doses and high ones, its poor bioavailability and suboptimal pharmacokinetics limited its use as anti-tumor agent in pre-clinical and clinical trials. To improve its applicability in cancer therapy, CUR (Curcumin) is encapsulated in PLGA (poly (lactic-co-glycolide)) (biodegradable polymer) nanoparticles, in the presence of PVA (poly (vinyl alcohol)) and PLL (poly (L-lysine)) stabilizers, using a nano-precipitation technique (Fig. 8). A curcumin
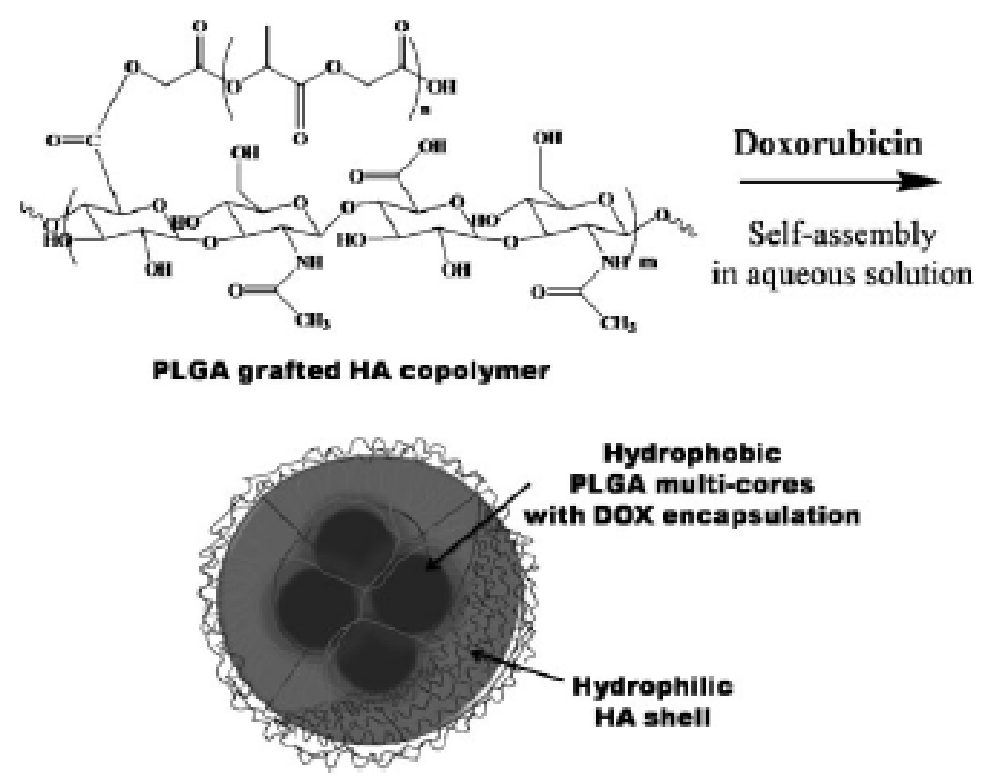

Fig. 7 Schematic representation of DOX-loaded HA-g-PLGA micelle nanoparticles [85]. 


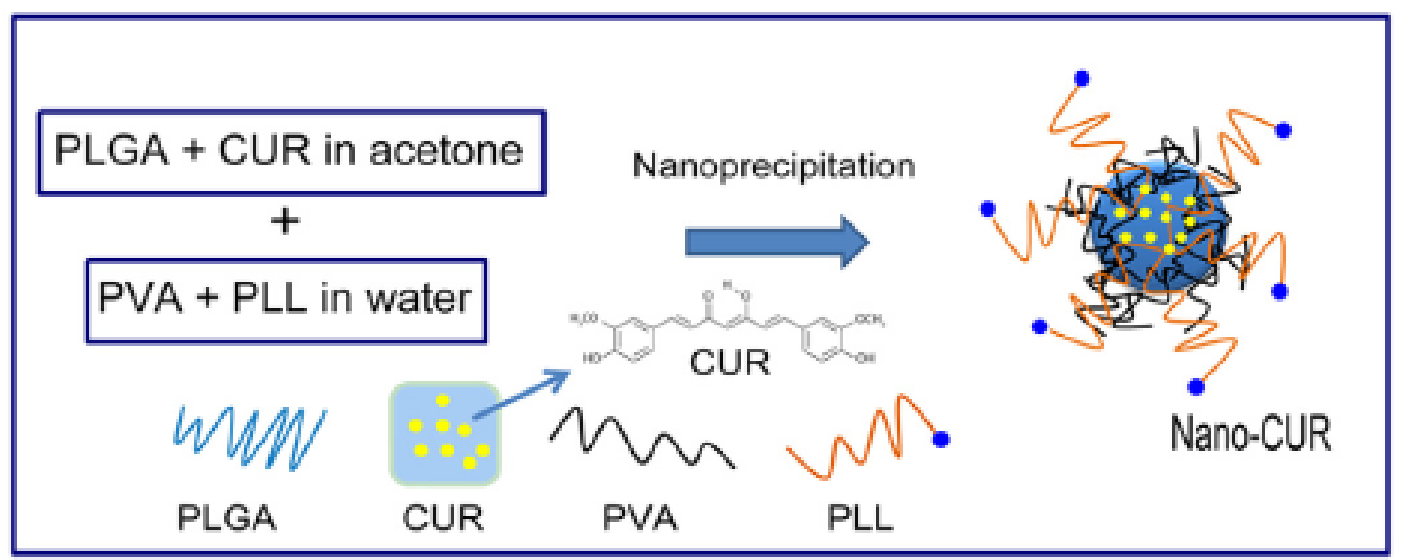

Fig. 8 Schematic representation of nano-curcumin (nano-CUR6) formulation preparation using nano-precipitation technique. PLGA and CUR were dissolved in acetone solvent and added drop wise to PVA/PLL containing aqueous solution to precipitate into fine nanoparticles. Curcumin is entrapped in core of PLGA nanoparticles [87].

(nano-formulation nano-CUR6) has demonstrated two and six fold increases in the cellular uptake performed in cisplatin resistant A2780CP ovarian and metastatic MDA-MB-231 breast cancer cells, respectively, compared to free curcumin $[86,87]$.

\subsection{Gemcitabine Hydrochloride Nanoparticles}

2, 2-difluorodeoxycytidine, GEM (Gemcitabine) is the first-choice drug in the treatment of pancreatic metastatic cancer. Gemcitabine is administered weekly as 30-minute infusion with starting dose ranging from 800 to $1250 \mathrm{mg} / \mathrm{m}^{2}$ [88]. Studies were carried out to develop starch NPs (nanoparticles) for the delivery of gemcitabine hydrochloride that could reduce its dose related side effects and may prolong its retention time $(24 \mathrm{~h})$ for the treatment of pancreatic cancer. It has been found that around $70 \%$ of drug was entrapped in nanoparticles. Tumor cells, hepatic Kupffer cells, and cells of the mononuclear phagocyte system have higher phagocytic rates for the uptake of nanoparticles than cells of other tissues, thus increasing the distribution of GEM in tumors, liver, and spleen [89].

\subsection{Aptamer-Nanomaterial Conjugates}

Aptamers are artificial nucleic acid ligands. They are short ssDNA (single-stranded DNA) or RNA oligonucleotides that bind to their targets with high selectivity and sensitivity because of their three-dimensional shape. Target molecules for aptamers can be virtually any class of substrate ranging from whole cells to large molecules, such as proteins, peptides, drugs, organic small molecules and metal ions. Aptamers can be used as selective binding molecules with high affinities in drug development, diagnostic and therapeutical research. Aptamers are used in combination with nanoparticles for biomedical sensing and detection, and as aptamer-nanoparticle conjugates for smart drug delivery. The aptamer-nanoparticle conjugates enable active controlled delivery of drugs that are incorporated in the nanoparticles once they are bound to a disease site because of the aptamer affinity to this site [90]. Farokhzad and co-workers have extensively studied the use of the anti-PSMA (prostate-specific membrane Antigen) A10 RNA aptamer, and its truncated version A10-3, to target nanoparticles [91]. In a pioneering nanoparticle-targeting study, they demonstrated that the A10-3 aptamer can be used to target poly (lactic acid) blockpolyethylene glycol copolymer nanoparticles to PSMA positive prostate cancer cells. The resulting nanomaterial showed a 77-fold increase in binding to PSMA expressing prostate cancer cells in comparison with untargeted nanoparticles. The A10-3 aptamer was again used to target modified PLGA (poly (D, L-lactic-co-glycolic acid)) 
nanoparticles to deliver docetaxol to prostate tumors in-vivo, where complete tumor regression was found [91].

\subsection{Dendrimer Nanoparticles}

Multifunctional cancer therapeutic nanodevices have been designed and synthesized using the PAMAM (poly (amidoamine)) dendrimer as a carrier. Partial acetylation of the G5 (generation 5) PAMAM dendrimer was utilized to neutralize a fraction of the primary amino groups, provide enhanced solubility of the dendrimer during the conjugation reaction of FITC (fluorescein isothiocyanate) (in DMSO (dimethyl sulfoxide), and prevent nonspecific targeting interactions (in vitro and in vivo) during delivery. The remaining nonacetylated primary amino groups were utilized for conjugation of the functional molecules FITC (fluorescein isothiocyanate, an imaging agent), FA (folic acid, targets overexpressed folate receptors on specific cancer cells), and MTX (methotrexate, chemotherapeutic drug) (Fig. 9). Additionally, dendrimer conjugates were characterized by multiple analytical methods including GPC (gel permeation chromatography), NMR (nuclear magnetic resonance spectroscopy), HPLC (high performance liquid chromatography), and UV spectroscopy. The fully characterized nanodevices can be used for the targeted delivery of chemotherapeutic and imaging agents to specific cancer cells [92].

Dendrimers conjugated with multiple functional molecules are being explored for use in a wide variety of biomedical applications, most prominently in the field of targeted drug delivery and imaging.

\section{Potential Toxicity of Nanoparticles}

Currently, most nanoparticles use nontoxic and biodegradable ingredients, thus the toxicities of the carrier molecules per se are expected to be mild. On the other hand, some nanoparticles lead to increased accumulation of drugs in the liver, spleen, and bone

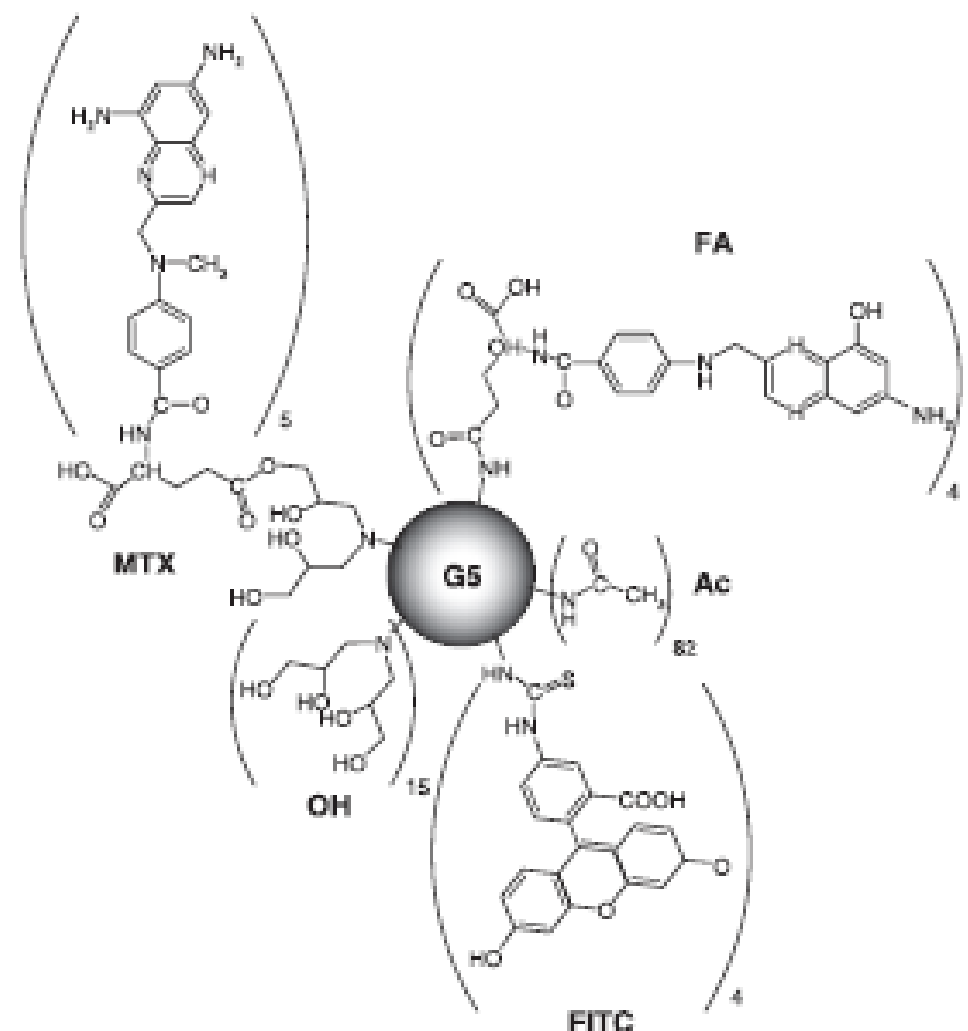

Fig. 9 Schematic of a multifunctional dendrimer labeled with FITC (fluorescien) for imaging, FA (folic acid) for targeting, MIX (methotrexate) for therapeutic delivery, and $\mathrm{OH}$ (alcohol) and Ac (acetylated) moieties for partical stabilization [92]. 
marrow, with the possibility of high toxicities to these organs. Many studies documented that the liver is the primary organ responsible for reticuloendothelial capture of nanoparticles, often due to phagocytosis by Kupffer cells [93, 94]. Hepatic uptake has been shown to be a main mechanism of hepatic clearance from the blood circulation following the intravenous injection of nanoparticles. In addition to hepatic accumulation, some nanoparticles have been reported to cause liver injury (decreased function and hepatic morphology changes) [95, 96]. For example, intravenous administration of cationic PAMAM dendrimers caused liver injury when administered intravenously to mice [94]. Hepatotoxicity has also been observed in mice treated orally with nano-zinc particles [97]. Also there are safety concerns with particular nanoparticles that are able to cross the blood brain barrier.

Attempts are being made to decrease the uptake of nanoparticles by MPS cells and to increase their accumulation in the active site through polymer or nanoparticle surface modifications, and/or incorporating targeting ligands [98-100]. With more rational design, many nanoparticles have shown an improved safety profile and enhanced antitumor efficacy compared with free drugs in preclinical and clinical studies [101-104]. For example, Doxil (PEG liposome loaded with doxorubicin) showed a reduction in cardiotoxicity over that of doxorubicin in a clinical study [105, 106]. Abraxane (albumin nanoparticle loaded with paclitaxel) showed a greater therapeutic outcome compared with free paclitaxel and taking advantage of the water solubility of the nanoparticle, successfully eliminated the side effects associated with the toxic vehicle Cremophor EL [46].

\section{Implications and Future Directions}

Nanoparticles provide a bright future of new generation of cancer therapeutics. Furthermore, the development of multifunctional nanoparticles may eventually render nanoparticles able to detect and kill cancer cells simultaneously. Thus, further understanding and studying in nanotechnology will certainly lead to the more rational design of optimized nanoparticles with improved selectivity, efficacy, and safety.

\section{Conclusion}

Cancer disease is still an extremely complex disease. In the last decade, there are many new approved drugs and hundreds of agents are still under clinical trials aiming to get rid of this malignant disease. The nanoparticle drug delivery systems is more advantageous than the other clinical approaches for cancer therapy since the ability to specifically target nanoparticles along with the controlled delivery of a therapeutic payload provides powerful new ways to treat cancer disease. Also, the development of multifunctional nanoparticles that are able to carry imaging agents and deliver multiple drugs enhanced the detection and treatment of cancer. The application of nanotechnology to cancer has already produced some exciting results and holds even greater promise for cancer patients in the future.

\section{Acknowledgements}

The authors express their sincere thanks to National Research Centre, Dokki, Giza and for its library for collecting all information and knowledge in this review article.

\section{References}

[1] Bhushan, B. 2010. Introduction to Anotechnology, Springer Handbook of Nanotechnology. (3rd ed.) New York: Springer, 1-13.

[2] Wang, X., Yang, L., Chen, Z. G., and Shin, D. M. 2008. "Application of Nanotechnology in Cancer Therapy and Imaging.” CA Cancer J. Clin. 58: 97-110.

[3] Brigger, I., Dubernet, C., and Couvreur, P. 2002. "Nanoparticles in Cancer Therapy and Diagnosis." Adv. Drug Deliv. Rev. 54: 631-51.

[4] Cegnar, M., Premzl, A., Zavasnik-Bergant, V., Kristl, J., and Kos, J. 2004. "Poly (Lactide-Co-Glycolide) Nanoparticles as a Carrier System for Delivering Cysteine Protease Inhibitor Cystatin into Tumor Cells.” Exp. Cell Res. 301: 223-31. 
[5] Liu, Y., Miyoshi, H., and Nakamura, M. 2007. "Nanomedicine for Drug Delivery and Imaging: A Promising Avenue for Cancer Therapy and Diagnosis Using Targeted Functional Nanoparticles.” Int. J. Cancer 120: 2527-37.

[6] Hull, L. C., Farrell, D., and Grodzinski, P. 2013. "Highlights of Recent Developments and Trends in Cancer Nanotechnology Research-View from NCI Alliance for Nanotechnology in Cancer.” Biotechnol. Adv. 32: 666-78.

[7] Shi-Yong, Z., Yao, W., Bin, H., Kui, L., and Zhong-Wei, G. 2014. "Biodegradable Polymeric Nanoparticles Based on Amphiphilic Principle: Construction and Application in Drug Delivery.” Sci. China Chem 57: 461-75.

[8] Wang, D., Lin, B., and Ai, H. 2013. "Theranostic Nanoparticles for Cancer and Cardiovascular Applications.” Pharm. Res. 31: 1390-406.

[9] Babu, A., Templeton, K. A., Munshi, A., and Ramesh, R. 2013. "Nanoparticle-Based Drug Delivery for Therapy of Lung Cancer: Progress and Challenges.” J. Nanomater 2013: 1-11.

[10] Blasiak, B., Veggel, C. F., and Tomanek, B. 2013. "Applications of Nanoparticles for MRI Cancer Diagnosis and Therapy.” J. Nanomater 2013: 12. doi:10.1155/2013/148578.

[11] Li, C. A. 2014. "Targeted Approach to Cancer Imaging and Therapy.” Nat. Mater. 13: 110-5.

[12] Xie, H., Li, H., Huang, Y., Wang, X., Yin, Y., and Li, G. 2014. "Combining Peptide and DNA for Protein Assay: CRIP1 Detection for Breast Cancer Staging.” ACS Appl. Mater Interfaces 6: 459-63.

[13] Xu, W., Min, W., and Zhao, J. X. 2014. "Recent Development of Silica Nanoparticles as Delivery Vectors for Cancer Imaging and Therapy.” Nanomed-Nanotechnol 10: 297-312.

[14] Lipinsky, C. A. 2000. "Drug-Like Properties and the Causes of Poor Solubility and Poor Permeability." $J$. Pharmacol. Toxicol. Methods 44: 235-49.

[15] Wilting, J., Hawighorst, T., Hecht, M., Christ, B., and Papoutsi, M. 2005. "Development of Lymphatic Vessels: Tumour Lymphangiogenesis and Lymphatic Invasion.” Curr. Med. Chem. 12: 3043-53.

[16] Reddy, L. H. 2005. "Drug Delivery to Tumors: Recent Strategies.” J. Pharm. Pharmacol. 57: 1231-42.

[17] Grossman, J. H., and McNeil, S. E. 2012. "Nanotechnology in Cancer Medicine." Phys. Today 65: 38-42.

[18] O’Neal, D. P., Hirsch, L. R., Halas, N. J., Donald Paynea, J., and West J. L. 2004. "Photo-Thermal Tumor Ablation in Mice Using Near Infrared-Absorbing Nanoparticles.” Cancer Lett. 209: 171-6.

[19] Moghimi, S. M., Hunter, A. C., and Murray, J. C. 2005.
"Nanomedicine: Current Status and Future Prospects." FASEB Journal 19: 311-30.

[20] Love, J. C., Estroff, L. A., Kriebel, J. K., Ralph, G., Nuzzo, R. G., and Whitesides, G. M. 2005. "Self-Assembled Onolayers of Thiolates on Metals as a Form of Nanotechnology.” Chem. Rev. 105: 1103-69.

[21] McNeil, S. E. 2005. "Nanotechnology for the Biologist." J. Leukoc. Biol. 78: 585-94.

[22] Hilgenbrink, A. R. 2005. "Low PS. Folate Receptor-Mediated Drug Targeting: From Therapeutics to Diagnostics.” J. Pharm. Sci. 94: 2135-46.

[23] Thomas, T. P., Majoros, I. J., Kotlyar, A., Kukowska-Latallo, J. F., Bielinska, A., Myc, A., and Baker, J. R. 2005. "Targeting and Inhibition of Cell Growth by an Engineered Dendritic Nanodevice.” J. Med. Chem. 48: 3729-35.

[24] Lin, M. Z., Teitell, M. A., and Schiller, G. J. 2005. “The Evolution of Antibodies into Versatile Tumor-Targeting Agents.” Clin. Cancer Res. 11: 129-38.

[25] Liu, Y., Miyoshi, H., and Nakamura, M. 2007. "Nanomedicine for Drug Delivery and Imaging: A Promising Avenue for Cancer Therapy and Diagnosis Using Targeted Functional Nanoparticles.” Int. J. Cancer 120 (12): 2527-37.

[26] Moschwitzer, J., and Muller, R. H. 2006. "New Method for the Effective Production of Ultrafine Drug Nanocrystals.” J. Nanosci. Nanotechnol. 6: 3145-53.

[27] Muller, R. H., and Keck, C. M. 2004. "Challenges and Solutions for the Delivery of Biotech Drugs-A Review of Drug Nanocrystal Technology and Lipid Nanoparticles.” J. Biotechnol. 113: 151-70.

[28] Jaiswal, J. K., Mattoussi, H., Mauro, J. M., and Simon, S. M. 2003. "Long-Term Multiple Color Imaging of Live Cells Using Quantum Dot Bioconjugates." Nat. Biotechnol. 21: 47-51.

[29] Akerman, M. E., Chan, W. C., Laakkonen, P., Bhatia, S. N., and Ruoslahti, E. 2002. "Nanocrystal Targeting in vivo.” Proc. Natl. Acad. Sci. USA 99: 12617-21.

[30] Alivisatos, P. 2004. "The Use of Nanocrystals in Biological Detection.” Nat. Biotechnol. 22: 47-52.

[31] Michalet, X., Pinaud, F. F., Bentolila, L. A., Tsay, J. M., Doose, S., Li, J. J., Sundaresan, G., Wu, A. M., Gambhir, S. S., and Weiss, S. 2005. "Quantum Dots for Live Cells, in vivo Imaging, and Diagnostics.” Science 307: 538-44.

[32] Bharali, D. J., Khalil, M., Gurbuz, M., Simone, T. M., and Mousa, S. A. 2009. "Nanoparticles and Cancer Therapy: A Concise Review with Emphasis on Dndrimers.” Int. J. Nanomedicine 4: 1-7.

[33] Alivisatos, A. P., Gu, W., and Larabell, C. 2005. "Quantum Dots As Cellular Probes.” Ann. Rev. Biomed Eng. 7: 55-76.

[34] Hoshino, A., Fujioka, K., Oku, T., Nakamura, S., Suga 
M., Yamaguchi, Y., Suzuki, K., Yasuhara, M., and Yamamoto, K. 2004. "Quantum Dots Targeted to the Assigned Organelle in Living Cells.” Microbiol. Immunol. 48: 985-94.

[35] Howarth, M., Takao, K., Hayashi, Y., and Ting, A. Y. 2005. "Targeting Quantum Dots to Surface Proteins in Living Cells with Biotin Ligase.” Proc. Natl. Acad. Sci. USA 102: 7583-8.

[36] Goldberg, M., Langer, R., and Jia, X. 2007. "Nanostructured Materials for Applications in Drug Delivery and Tissue Engineering.” J. Biomater. Sci. Polym. Ed. 18: 241-68.

[37] Gao, X., Cui, Y., Levenson, R. M., Chung, L. W., and Nie, S. 2004. "In vivo Cancer Targeting and Imaging with Semiconductor Quantum Dots.” Nat. Biotechnol. 22: 959-60.

[38] Bagalkot, V., Zhang, L., Levy-Nissenbaum, E., Jon, S., Kantoff, P. W., Langer, R., and Farokhzad, O. C. 2007. “Quantum Dot-Aptamer Conjugates for Synchronous Cancer Imaging, Therapy, and Sensing of Drug Delivery Based on Bi-fluorescence Resonance Energy Transfer.” Nano. Lett. 7: 3065-70.

[39] Frangioni, J. V. 2003. "In vivo Near-Infrared Fluorescence Imaging.” Curr. Opin. Chem. Biol. 7: 626-34.

[40] Martin C. R., and Kohli, P. 2003. "The Tmerging Field of Nanotube Biotechnology.” Nat. Rev. Drug Discov. 2: 29-39.

[41] Sapra, P., Tyagi, P., and Allen, T. M. 2005. "Ligand-Targeted Liposomes for Cancer Treatment." Curr. Drug Deliv. 2: 369-81.

[42] Ferrari, M. 2005. "Cancer Canotechnology: Opportunities and Challenges.” Nat. Rev. Cancer 5: 161-71.

[43] Fassas, A., and Anagnostopoulos, A. 2005. "The Use of Liposomal Daunorubicin (DaunoXome) in Acute Myeloid Leukemia.” Leuk Lymphoma 46: 795-802.

[44] Charrois, G. J., and Allen, T. M. 2004. "Drug Release Rate Influences the Pharmacokinetics, Biodistribution, Therapeutic Activity, and Toxicity of Pegylated Liposomal Doxorubicin Formulations in Murine Breast Cancer.” Biochim. Biophys. Acta. 1663: 167-77.

[45] Hofheinz, R. D., Gnad-Vogt, S. U., Beyer, U., and Hochhaus, A. 2005. "Liposomal Encapsulated Anti-cancer Drugs.” Anticancer Drugs 16: 691-707.

[46] Allison, S. D. 2007. "Liposomal Drug Delivery.” J. Infus. Nurs. 30: 89-95.

[47] Gradishar, W. J., Tjulandin, S., Davidson, N., Shaw, H., Desai, N., Bhar, P., Hawkins, M., and O’Shaughnessy, J. 2005. "Phase III Trial of Nanoparticle Albumin-Bound Paclitaxel Compared with Polyethylated Castor Oilbased Paclitaxel in Women with Breast Cancer.” J. Clin. Oncol. 23: 7794-803.
[48] Chen, C., Yu, C. H., Cheng, Y. C., Yu, P. H., and Cheung, M. K. 2008. "Micelle Formation and Sol-Gel Transition Behavior of Comb-Like Amphiphilic Poly ((PLGA-b-PEG) MA) Copolymers.” J. Polym. Sci. Part A: Polym. Chem. 46: 1954-63.

[49] Park, I., Lee, H., Chang, T., and Kim, S., W., and Lee, D. S. 2002. "Poly (D,L-lactic acid-co-glycolic acid)-b-poly (ethylene glycol)-b-poly (D,L-lactic acid-co-glycolic acid) Triblock Copolymer and Thermoreversible Phase Transition in Water.” J. Biomed. Mater Res. 61: 188-96.

[50] Lee, S. J., Han, B. R., Park, S. Y., Han, D. K., and Kim, S. C. 2006. "Sol-Gel Transition Behavior of Biodegradable Three-Arm and Four-Arm Star-Shaped PLGA-PEG Block Copolymer Aqueous Solution.” J. Polym. Sci Part A: Polym. Chem. 44: 888-99.

[51] Yallapu, M. M., Gupta, B. K., Jaggi, M., and Chauhan, S. C. 2010. "Fabrication of Curcumin Encapsulated PLGA Nanoparticles for Improved Therapeutic Effects in Metastatic Cancer Cells.” J. Colloid Interface Sci. 351: 19-29.

[52] Svenson, S., and Tomalia, D. A. 2005. "Dendrimers in Biomedical Applications-Reflections on the Field." Adv. Drug Deliv. Rev. 57: 2106-29.

[53] Bharali, D. J., Lucey, D. W., Jayakumar, H., Pudavar, H. E., and Prasad, P. N. 2005. "Folate-Receptor-Mediated Delivery of InP Quantum Dots for Bioimaging Using Confocal and Two-Photon Microscopy.” J. Am. Chem. Soc. 127: 11364-71.

[54] Jaishree, V., and Gupta, P. D. 2012. "Nanotechnology: A Revolution in Cancer Diagnosis.” Ind. J. Clin. Biochem. 27: 214-20.

[55] Bai, S., Thomas, C., Rawat, A., and Ahsan, F. 2006. "Recent Progress in Dendrimer-Based Nanocarriers." Crit. Rev. Ther Drug Carrier Syst. 23: 437-95.

[56] Bharali, D. J., Khalil, M., Gurbuz, M., Simone, T. M., and Mousa, S. A. 2009. "Nanoparticles and Cancer Therapy: A Concise Review with Emphasis on Dendrimers.” Int. J. Nanomedicine 4: 1-7.

[57] Manchester, M., and Singh, P. 2006. "Virus-Based Nanoparticles (VNPs): Platform Technologies for Diagnostic Imaging.” Adv Drug Deliv Rev 58: 1505-22.

[58] Cai, W., Shin, D. W., Chen, K., Gheysens, O., Cao, Q., Wang, S. X., Gambhir, S. S., and Chen, K. 2006. "Peptide-Labeled Near-Infrared Quantum Dots for Imaging Tumor Vasculature in Living Subjects.” Nano. Lett. 6: 669-76.

[59] Zhu, D., Liu, F., Ma, L., Liu, D., and Wang, Z. 2013. "Nanoparticle-Based Systems for $\mathrm{T}_{1}$-Weighted Magnetic Resonance Imaging Contrast Agents.” Int. J. Mol. Sci. 14: 10591-607.

[60] Kanematsu, M., Kondo, H., Goshima, S., Kato, H., Tsuge, U., Hirose, Y., Kim, M. J., and Moriyama, N. 2006. 
“Imaging Liver Metastases: Review and Update.” Eur. J. Radiol. 58: 217-28.

[61] Keller, T. M., Michel, S. C., Frohlich, J., Fink, D., Caduff, R., Marincek, B., and Kubik-Huch, R. A. 2004. "USPIO-Enhanced MRI for Preoperative Staging of Gynecological Pelvic Tumors: Preliminary Results.” Eur. Radiol. 14: 937-44.

[62] Bischof Delaloye, A. 2000. "Radioimmunoimaging and Radioimmunotherapy: Will These Be Routine Procedures?" Semin, Nucl. Med. 30: 186-94.

[63] Ascencio, J. A., Rincon, A. C., and Canizal, G. 2005. "Synthesis and Theoretical Analysis of Samarium Nanoparticles: Perspectives in Nuclear Medicin,” J. Phy. Chem. B. 109: 8806-12.

[64] Medina, O. P., Zhu, Y., and Kairemo, K. 2004. "Targeted Liposomal Drug Delivery in Cancer.” Curr. Pharm. Des. 10: 2981-9.

[65] Torchilin, V. P. 2006. "Multifunctional Nanocarriers." Adv. Drug Deliv. Rev. 58: 1532-55.

[66] Waxman, S., Ishibashi, F., and Muller, J. E. 2006. "Detection and Treatment of Vulnerable Plaques and Vulnerable Patients, Novel Approaches to Prevention of Coronary Events.” Circulation 114: 2390-411.

[67] Pissuwan, D., Valenzuela, S. M., and Cortie, M. B. 2006. "Therapeutic Possibilities of Plasmonically Heated Gold Nanoparticles.” Trends Biotechnol. 24: 62-7.

[68] Jang, B., Park, J., Tung, C., Kim, I., and Choi, Y. 2011. "Gold Nanorod-Photosensitizer Complex for Near-Infrared Fluorescence Imaging and Photodynamic/Photothermal Therapy In Vivo." ACS NANO 5: 1086-94.

[69] Jain, S., Hirst, G., and O’Sullivan, M. 2012. “Gold Nanoparticles as Novel Agents for Cancer Therapy.” The Br. J. Radiol. 85: 101-13.

[70] Thanh, N. T. K., and Rosenzweig, Z. 2002. "Development of an Aggregation-Based Immunoassay for Anti-protein, a Using Gold Nanoparticles.” Anal. Chem. 74: 1624-8.

[71] Bendayan, M. 2001. "Worth Its Weight in Gold.” Science 291: 1363-5.

[72] Nam, J., Thaxton, S., and Mirkin, C. A. 2003. "Nanoparticle-Based Bio-bar Codes for the Ultrasensitive Detection of Proteins.” Science 301: 1884-6.

[73] Zhao, X., Hilliar, L. R., Mechery, S. J., Wang, Y., Bagwe, R. P., Jin, S., and Tan, W. A. 2004. "Rapid Bioassay for Single Bacterial Cell Quantitation Using Bioconjugated Nanoparticles.” Proc Natl Acad Sci USA 101: 15027-32.

[74] Loo, C., Lin, A., Hirsch, L. R., Lee, M. H., Barton, J., Halas, N. J., West, J. L., and Drezek, R. 2004. "Nanoshell-Enabled Photonics-Based Imaging and Therapy of Cancer." Technol. Cancer Res. Treat. 3: 33-40.
[75] El-Sayed, I. H., Huang, X., and El-Sayed, M. A. 2005. "Surface Plasmon Resonance Scattering and Absorption of Anti-EGFR Antibody Conjugated Gold Nanoparticles in Cancer Diagnostics: Applications in Oral Cancer.” Nano. Lett. 5: 829-34.

[76] Sershen, S. R., Westcott, S. L., Halas, N. J., and West, J. L. 2000. "Temperature-Sensitive Polymer-Nanoshell Composites for Photothermally Modulated Drug Delivery.” J. Biomed Mater Res. 51: 293-8.

[77] Jolesz, F. A., and Hynynen, K. 2002. "Magnetic-Resonance Image Guided Focused Ultrasound Surgery.” Cancer J. 8: S100-12.

[78] West, J. L., and Halas, N. J. 2003. "Engineered Nanomaterials for Biophotonics Applications: Improving Sensing, Imaging, and Therapeutics.” Annu. Rev. Biomed Eng. 5: 285-92.

[79] Hirsch, L. R., Stafford, R. J., Babkson, J. A., Sershen, S. R., Rivera, B., Price, R. E., Hazle, J. D., Halas, N. T., and Wes, J. L. 2003. “Nanoshell-Mediated Near-Infrared Thermal Therapy of Tumors under Magnetic Resonance Guidance.” Proc. Natl. Acad. Sci. USA 100: 13549-54.

[80] Glomm, W. R. 2005. "Functionalized Gold Nanoparticles for Application in Biotechnology.” J. Disp. Sci. Tech. 26: 389-414.

[81] Kohler, N., Sun, C., Wang, J., and Zhang, M. 2005. "Methotrexate-Modified Superparamagnetic Nanoparticles and Their Intracellular Uptake into Human Cancer Cells.” Langmuir 21: 8858-64.

[82] Yoo, H. S., and Park, T. G. 2000. "In Vitro and In Vivo Anti-tumor Activities of Nanoparticles Based on Doxorubicin-PLGA Conjugates.” Polym. Prepr. 41: 9923.

[83] Brannon-Peppas, L., and Blanchette, J. O. 2004. "Nanoparticle and Targeted Systems for Cancer Therapy.” Adv. Drug Deliv. Rev. 56: 1649-59.

[84] Bhadra, D., Bhadra, S., Jain, S., and Jain, N. K. 2003. “A PEGylated Dendritic Nanoparticulate Carrier of Fluorouracil.” Int. J. Pharm. 257: 111-24.

[85] Lee, H., Ahn, C., and Park, T. G. 2009. "Poly [lactic-co-(glycolic acid)]-Grafted Hyaluronic Acid Copolymer Micelle Nanoparticles for Target-Specific Delivery of Doxorubicin.” Macromol. Biosci. 9: 336-42.

[86] Yallapu, M. M., Jaggi, M., and Chauhan, S. C. 2010. "Scope of Nanotechnology in Ovarian Cancer Therapeutics.” J. Ovarian. Res. 3: 19.

[87] Yallapu, M. M., Gupta, B. K., Jaggi, M., and Chauhan, S. C. 2010. "Fabrication of Curcumin Encapsulated PLGA Nanoparticles for Improved Therapeutic Effects in Metastatic Cancer Cells.” J. Colloid Interface Sci. 351 (1): 19-29.

[88] Reddy, L. H., and Couvreur, P. 2008. "Novel Approaches to Deliver Gemcitabine to Cancers.” Curr. Pharm. Des. 
14: 1124-37.

[89] Khaira, R., Sharma, J., and Saini, V. 2014. "Development and Characterization of Nanoparticles for the Delivery of Gemcitabine Hydrochloride." The Scientific World Journal 2014: article ID 560962.

[90] Reinemann, C., and Strehlitz, B. 2014. "Aptamer-Modified Nanoparticles and Their Use in Cancer Diagnostics and Treatment.” Swiss Med. Wkly. 114: w13908.

[91] Xiao, Z., and Farokhzad, O. C. 2012. "Aptamer-Functionalized Nanoparticles for Medical Applications: Challenges and Opportunities.” ACS Nano 6: 3670-6.

[92] Majoros, I. J., Thomas, T. P., Chandan, B., Mehta, C. B., and Baker, J. R. 2005. "Poly (amidoamine) Dendrimer-Based Multifunctional Engineered Nanodevice for Cancer Therapy.” J. Med. Chem. 48: 5892-9.

[93] Cagle, D. W., Kennel. S. J., Mirzadeh, S., Alford, J. M., Wilson, L. J. 1999. "In Vivo Studies of Fullerene Based Materials Using Endohedral Metallofullerene Radiotracers.” Proc. Natl. Acad. Sci. USA 96: 5182-7.

[94] Ogawara, K., Furumoto, K., Takakura, Y., Hashida, M., Higaki, K., and Kimura, T. 2001. "Surface Hydrophobicity of Particles Is Not Necessarily the Most Important Determinant in Their Vivo Disposition after Intravenous Administration in Rats.” J. Control Release 77: 191-8.

[95] Fernandez-Urrusuno, R., Fattal, E., Porquet, D., Feger, J., and Couvreur, P. 1995. "Evaluation of Liver Toxicological Effects Induced by Polyalkylcyano Acrylate Nanoparticles.” Toxicol. Appl. Pharmacol. 130: 272-9.

[96] Roberts, J. C., Bhalgat, M. K., and Zera, R. T. 1996. "Preliminary Biological Evaluation of Polyamidoamine (PAMAM) Star-Burst Dendrimers.” J. Biomed. Mater Res. 30: 53-65.

[97] Neerman, M. F., Zhang, W., Parrish, A. R., and Simanek, E. E. 2004. "In Vitro and In Vivo Evaluation of a
Melamine Dendrimer as a Vehicle for Drug Delivery.” Int. J. Pharm. 281: 29-32.

[98] Wang, B., Feng, W. Y., Wang, T. C., Jia, G., Wang, M., Shi, J. W., Zhang, F., Zhao, Y. L., and Chai, Z. F. 2006. "Acute Toxicity of Nano- and Micro-Scale Zinc Powder in Healthy Adult Mice.” Toxicol. Lett. 161: 115-23.

[99] Morose, G. 2010. "The 5 Principles of "Design for Safer Nanotechnology”.” J. Clean. Pro. 18: 285-9.

[100] Moorthi, C., Krishnan, K., Manavalan, R., and Kathiresan, K. 2012. "Preparation and Characterization of Curcumin-Piperine Dual Drug Loaded Nanoparticles.” Asian Pac. J. Trop. Biomed 2: 841-8.

[101] Moorthi, C., Manavalan, R., and Kathiresan, K. 2011. "Nanotherapeutics to Overcome Conventional Cancer Chemotherapy Limitations.” J. Pharm. Pharmaceutical Sci. 14: 67-77.

[102] Kukowska-Latallo, J. F., Candido, K. A., Cao, Z., Nigavekar, S. S., Majoros, I. J., Thomas, T. P., Balogh, L. P., Khn, M. K., and Baker, J. R. 2005. "Nanoparticle Targeting of Anticancer Drug Improves Therapeutic Response in Animal Model of Human Epithelial Cancer.” Cancer Res. 65: 5317-24.

[103] Benny, O., Fainaru, O., Adini, A., Cassiola, F., Bazinet, L., Adini, I., Pravda, E., Nahmias, Y., Koirala, S., Corfas, G., D’Amato, R. J., and Folkman, J. 2008. “An Orally Delivered Small-Molecule Formulation with Antiangiogenic and Anticancer Activity.” Nat. Biotechnol. 26: 799-807.

[104] Moorthi, C., and Krishnasamy, K. 2012. "Nanotoxicology: Toxicity of Engineered Nanoparticles and Approaches to Produce Safer Nanotherapeutics." Int. J. Pharma. Sci. 2: 117-22.

[105] Rahman, A. M., Yusuf, S. W., and Ewer, M. S. 2007. "Anthracycline-Induced Cardiotoxicity and the Cardiac-Sparing Effect of Liposomal Formulation.” Int. J. Nanomedicine 2: 567-83.

[106] Batist, G. 2007. "Cardiac Safety of Liposomal Anthracyclines.” Cardiovasc Toxicol. 7: 72-4. 